\title{
EDUCAÇÃO AMBIENTAL, CONSUMO E RESÍDUOS SÓLIDOS: AS CONCEPÇÕES DE PROFESSORAS DE EDUCAÇÃO INFANTIL
}

\author{
Natália Teixeira Ananias Freita ${ }^{1}$, Fátima Aparecida Dias Gomes Marin ${ }^{2}$ \\ ${ }^{1}$ Doutora em Educação pelo Programa de Pós-Graduação em Educação pela Universidade Estadual Paulista - UNESP, \\ campus de Presidente Prudente. Docente do Centro Educacional Ouro Preto-MG. ORCID iD: https://orcid.org/0000- \\ 0002-9915-7387 E-mail: nathyteixeira@hotmail.com \\ ${ }^{2}$ Doutora em Ensino na Educação Brasileira pela Universidade Estadual Paulista - UNESP, campus de Marília. Docente \\ do Departamento de Educação e do Programa de Pós-Graduação em Educação da Universidade Estadual Paulista - \\ UNESP, campus de Presidente Prudente. ORCID iD: https://orcid.org/0000-0001-6584-3656. E-mail: \\ fatimadiasgomes@gmail.com
}

\section{RESUMO}

O objetivo deste estudo consistiu em discutir a formação de professores e suas concepções e práticas pedagógicas diante da Educação Ambiental em Resíduos Sólidos no contexto da Educação Infantil. Os apontamentos metodológicos dizem respeito a abordagem qualitativa, do tipo "estudo de caso". Foram elencadas 10 professoras de pré-escola inseridas em Escolas Municipais de Educação Infantil como sujeitos da pesquisa e os dados foram obtidos com entrevistas semiestruturadas. Apresentamos neste artigo as discussões relativas às concepções pedagógicas sobre Educação Ambiental, Consumo e Resíduos Sólidos mencionadas pelas professoras de Educação Infantil. As concepções das professoras sobre Educação Ambiental perpassam o viés da Conscientização Ambiental, ligada à relação da criança com o meio em que vive. Em relação aos Resíduos Sólidos, as professoras conectam a temática com a reciclagem. A maioria das professoras compreende a distinção entre Consumo e Consumismo. Acreditamos que a Educação Ambiental em Resíduos Sólidos deve ser realizada na Educação Infantil a partir de situações cotidianas e norteadas por práticas pedagógicas adequadas às possibilidades de compreensão das crianças, o que inclui uma boa formação inicial e continuada dos professores a respeito das questões ambientais.

Palavras-chave: Educação Infantil. Educação Ambiental. Consumo. Resíduos Sólidos. Formação de Professores.

\section{ENVIRONMENTAL EDUCATION, CONSUMPTION AND SOLID WASTE: THE CONCEPTIONS OF CHILDREN EDUCATION TEACHERS}

\section{ABSTRACT}

The aim of this study was to discuss the formation of teachers and their conceptions and pedagogical practices in relation to Environmental Education in Solid Waste in the context of Early Childhood Education. The methodological notes concern the qualitative approach, of the "case study" type. Ten preschool teachers from the Municipal Schools of Kindergarten were listed as research subjects and the data were obtained through semi-structured interviews. In this article we present the discussions concerning the pedagogical conceptions about Environmental Education, Consumption and Solid Waste mentioned by the preschool teachers. The teachers' conceptions about Environmental Education permeate the bias of Environmental Awareness, linked to the child's relationship with the environment in which they live. Regarding Solid Waste, the teachers connect the theme with recycling. Most teachers understand the distinction between Consumption and Consumerism. We believe that Environmental Education in Solid Waste should be carried out in Early Childhood Education based on daily situations and guided by pedagogical practices appropriate to the children's possibilities of comprehension, which includes a good initial and continuous teacher training on environmental issues. 
Keywords: Early Childhood Education. Environmental education. Consumption. Solid waste. Teacher training.

\section{EDUCACIÓN AMBIENTAL, CONSUMO Y RESIDUOS SÓLIDOS: LAS CONCEPCIONES DE PROFESORES DE EDUCACIÓN INFANTIL}

\section{RESUMEN}

El objetivo de este estudio fue discutir la formación de docentes y sus concepciones y prácticas pedagógicas en relación con la Educación Ambiental en Residuos Sólidos en el contexto de la Educación Infantil. Las notas metodológicas se refieren al enfoque cualitativo, del tipo "estudio de caso". Diez maestros de preescolar de las Escuelas Municipales de la Primera Infancia se enumeraron como sujetos de investigación, y los datos se obtuvieron a través de entrevistas semiestructuradas. En este artículo presentamos las discusiones sobre las concepciones pedagógicas sobre Educación Ambiental, Consumo y Residuos Sólidos mencionados por los maestros de preescolar. Las concepciones de los maestros sobre la Educación Ambiental impregnan el sesgo de la Conciencia Ambiental, vinculada a la relación del niño con el entorno en el que vive. Con respecto a los desechos sólidos, los maestros conectan el tema con el reciclaje. La mayoría de los docentes comprenden la distinción entre consumo y consumismo. Creemos que la Educación Ambiental en Residuos Sólidos debe llevarse a cabo en la educación de la primera infancia basada en situaciones cotidianas y conduzidas prácticas pedagógicas apropiadas a las posibilidades de comprensión de los niños, lo que incluye una buena capacitación inicial y continua de maestros sobre temas ambientales.

Palabras-clave: Educación de la primera infância. Educación ambiental. Consumo. Residuos sólidos. Formación de profesores.

\section{INTRODUÇÃO}

Este artigo apresenta um recorte da Tese de Doutorado intitulada "Educação Ambiental, Consumo e Resíduos Sólidos no Contexto da Educação Infantil: um diálogo necessário com os professores", pertencente ao Programa de PósGraduação em Educação da Faculdade de Ciências e Tecnologia, Universidade Estadual Paulista (FCT/UNESP), Pres. Prudente - SP.

Partindo do princípio que a Educação Ambiental em Resíduos Sólidos é relevante para à formação das crianças inseridas no contexto da Educação Infantil, esta pesquisa teve como motivação compreender como acontece a Educação Ambiental em Resíduos Sólidos e Consumo no contexto da Educação Infantil e quais são as concepções e práticas das professoras da pré-escola inseridas em Escolas Municipais de Educação Infantil de um município do interior do Estado de São Paulo.

Diante de inúmeras reflexões emergentes na sociedade, constata-se 0 anseio em sensibilizar as pessoas a respeito dos problemas ambientais existentes e de fomentar a participação de todos no sentido de amenizá-los ou resolvê-los. "[...] A preservação do meio ambiente depende de uma consciência ecológica e a formação da consciência ecológica depende da educação." (GADOTTI, 2010, p. 62).

Indivíduos mais preparados e conscientes no que tange a importância de uma Educação voltada para o ambiente, colaboram significativamente para uma sociedade mais justa e humanizada. Por consequência, a inserção de profissionais na Educação Infantil preparados e engajados no compromisso de formar cidadãos preocupados com o ambiente em que vivem, colabora com o planeta. Defendemos o slogan "pensar globalmente e agir localmente" no âmbito da Educação Infantil.

É fundamental valorizar o local em que a criança está inserida e proporcionar vivências que levem à aquisição de valores, saberes e atitudes voltadas para a conservação do ambiente. Para tanto, é necessário investir na formação profissional.

Consideramos oportuno que a criança sinta-se parte integrante da natureza, que tenha vivências com a natureza e no que diz respeito aos Resíduos Sólidos, que compreenda o tema numa perspectiva de ciclo, desde a extração da matéria prima para fabricação dos produtos usados no seu cotidiano até as consequências do descarte no meio ambiente. A modificação de nossos posicionamentos a respeito do consumo, 
da produção e descarte de resíduos desde a infância é essencial. Neste sentido, retomamos a importância de reorientar o nosso estilo de vida, a partir de valores éticos.

O objetivo da pesquisa foi analisar como ocorre a Educação Ambiental em Resíduos Sólidos no contexto da Educação Infantil (préescola), a partir da formação, concepções e práticas pedagógicas das professoras. Contudo, neste artigo, apresentamos os dados referentes às concepções pedagógicas das professoras a respeito da Educação Ambiental, Consumo e Resíduos Sólidos.

A seguir, destacamos o delineamento metodológico de nossa pesquisa.

\section{DELINEAMENTO METODOLÓGICO}

Os apontamentos metodológicos utilizados no desenvolvimento da pesquisa são de abordagem qualitativa, conforme Demo (2005) e Severino (2007), e a pesquisa é caracterizada como do tipo "Estudo de caso", de acordo com Lüdke e André (1986).

Alonso (2016) ressalta alguns aspectos presentes na pesquisa qualitativa: os fenômenos sociais são considerados; os sujeitos da pesquisa são ativos no processo de coleta de dados; o pesquisador interpreta os dados com base na realidade dos sujeitos pesquisados e o objeto pesquisado modifica-se na presença do pesquisador.

Ao relacionarmos esses pontos com a nossa pesquisa, foi possível considerar a inserção das professoras dentro de um ambiente educativo; os sujeitos participaram ativamente; os dados coletados foram interpretados a luz das concepções e práticas das professoras de préescola a respeito da Educação Ambiental, Consumo e Resíduos Sólidos e, por fim, constatamos indícios de reflexão por parte das professoras ao discorrerem sobre as suas concepções e práticas.

Lüdke e André (1986) afirmam que por meio do estudo de caso, o pesquisador possui a possibilidade de explorar um caso único e particular, considerando a importância do caso e que, a partir das interpretações deste caso é possível a construção de novos saberes, ampliar o conhecimento de um fenômeno ou resolver um problema.

A coleta de dados foi realizada por meio de entrevistas semiestruturadas com 10 professoras que atuavam em Escolas Municipais de Educação Infantil, salas de pré-escola (crianças de 4 a 5 anos) pertencentes a um município do interior do Estado de São Paulo (Brasil). A escolha das professoras foi realizada a partir de uma amostra das Escolas Municipais de Educação Infantil pertencentes as cinco regiões da cidade investigada (Norte, Sul, Leste, Oeste e Centro), considerando 5 escolas, 2 professoras pertencentes a cada uma delas.

Foram levantados questionamentos sobre as concepções e práticas que as professoras tinham sobre Consumo e Resíduos Sólidos; materiais utilizados nas atividades de Educação Ambiental; formação inicial e continuada em Educação Ambiental, Consumo e Resíduos Sólidos; realização de Projetos Educativos sobre Educação Ambiental, Consumo e Resíduos Sólidos, além de discussões sobre a inserção e importância da Educação Ambiental na Educação Infantil.

Os dados foram transcritos e agrupados em categorias. Nossas análises foram pautadas no referencial teórico, nos documentos oficiais sobre a Educação Infantil e a Educação Ambiental e nos dados obtidos com as entrevistas.

É digno de menção que a realização da pesquisa teve aprovação do Comitê de Ética e Pesquisa da FCT/UNESP, conforme parecer consubstanciado CAAE: 52627515.1.0000.5402.

A seguir, apresentamos e analisamos os dados coletados a respeito das concepções das professoras entrevistadas.

\section{RESULTADOS E DISCUSSÃO}

A Educação Ambiental no Brasil é fruto de discussões e de documentos resultantes de eventos nacionais e internacionais sobre o meio ambiente que ocorreram após 1970. Antes desse período, o meio ambiente era um tema presente nos discursos dos ambientalistas e pauta de movimentos sociais.

Os eventos "Rio 92", "Rio+10" e "Rio+20" ocorridos no Brasil, trouxeram contribuições significativas para a difusão da Educação Ambiental no país. As pesquisas acadêmicas de Educação Ambiental produzidas pelos Programas de Pós-Graduação, nas mais diversas áreas, tornaram-se expressivas.

No entanto, mesmo considerando a Política Nacional de Educação Ambiental (BRASIL, 1999) e as Diretrizes Curriculares Nacionais para a Educação Ambiental (BRASIL, 2012) que preconizam a obrigatoriedade da Educação Ambiental em todos os níveis de ensino, a 
Educação Ambiental na Educação Infantil ainda comparece em segundo plano.

A Educação Ambiental ainda é uma temática recente na formação dos professores, conforme demonstraram as pesquisas de Bortolozzi e Peres Filho (2000), Araújo (2005), Lambertucci (2008) e Mielke (2010).

Léa Tiriba (2005) aponta em seus estudos a importância da inserção da Educação Ambiental no contexto da Educação Infantil, destacando que: "[...] creches e pré-escolas são espaços privilegiados para aprender-ensinar porque lá as crianças colhem suas primeiras sensações, impressões, sentimentos do viver." (TIRIBA, 2005, p. 2).

É fundamental uma Educação Infantil que valorize o ambiente em que a criança está inserida e proporcione atividades e vivências que levem a aquisição de hábitos, valores, saberes e atitudes em prol das questões ambientais. Para tanto, é necessário também à formação de profissionais e professores da Educação Infantil que atendam a esta necessidade apontada pela sociedade em que vivemos, ou seja, um contexto social, político e educacional que requer mais atenção com relação ao meio ambiente.

Barros e Tozzoni-Reis (2009) afirmam em seus estudos sobre a Educação Infantil a necessidade de se reinventar o contexto em que as crianças vivenciam a Educação Infantil, ou seja, um período de formação que priorize as questões ambientais e, principalmente, acrescentar ao contexto educacional a dimensão ambiental.

Máximo-Esteves (1998, p. 47) afirma: “[...] os alunos hão de assim entender que um problema local não pode ser entendido apenas como algo circunscrito a esse local. Quando as ações são dirigidas para os problemas locais, não pode deixar de se pensar globalmente". A partir desta afirmação, compreender o tema Consumo e Resíduos Sólidos no cotidiano das crianças considerando sua realidade, possibilita maior vivência e entendimento dos problemas locais que afetam o meio em que vivem, propiciando assim, reflexões sobre o meio ambiente de um modo geral.

Considerando as discussões expostas, acreditamos que a Educação Ambiental é fundamental para o desenvolvimento das crianças. No entanto, os estudos de Rodrigues (2011), Ruffino (2003) e Capitulino e Almeida (2014) apontam para uma supervalorização da temática ambiental somente no Ensino Fundamental, o que requer uma modificação curricular e documental, para que aconteça, de fato, a Educação Ambiental na Educação Infantil e em todos os níveis de ensino.

Loureiro (2011) afirma que não é correto considerarmos a Educação Ambiental como uma "receita de bolo" para todos os problemas ambientais. $\mathrm{O}$ autor explica primeiramente que é importante evitarmos a utilização de clichês, tais como "Educação é a solução", na medida em que a educação não age isoladamente e sofre modificações da sociedade constantemente. Num segundo aspecto, o indivíduo deve assumir seu papel no meio ambiente, enquanto ser individual, social, do Estado, país e membro planetário, considerando suas ações em todas essas esferas e não somente no contexto individual.

O terceiro ponto apontado por Loureiro (2011) diz respeito a uma Educação Ambiental realizada em conexão com o local em que se vive, por meio de projetos sociais que levem a ação e a reflexão sobre os problemas ambientais a partir do contexto local para o global.

O quarto aspecto enfatiza a preocupação que cada pessoa deve ter a respeito de sua participação no meio ambiente de forma individual e coletiva. As relações dos indivíduos e o meio em que vivem devem ocorrer em harmonia com os recursos naturais. Por fim, o autor afirma a importância de que todos os indivíduos lutem por um meio ambiente sadio e equilibrado, conforme preconiza a Constituição Federal de 1988, e destaca que este aspecto da legislação é deixado em segundo plano por muitas ações sociais.

Se desejamos uma sociedade mais consciente, a educação e a mudança de hábitos em prol ao meio ambiente necessariamente devem ser inseridos no contexto de nossas crianças. O cumprimento da Educação Ambiental na Educação Infantil é direito de todas as crianças e não mais como um tema a ser desenvolvido por "modismo" ou "tendência", conforme estabelece a Política Nacional de Educação Ambiental, Lei no9795/99. (BRASIL, 1999).

Portilho (2005) enfatiza que a Sociedade do consumo na qual fazemos parte e que é responsável na produção e comercialização de produtos e serviços para nossa subsistência colabora também para a disseminação de uma Cultura do Consumo, que induz os indivíduos a consumirem cada vez mais o que é disponibilizado pelo mercado. Dificilmente são realizadas reflexões sobre a origem dos produtos, a necessidade ou não de se possuir um 
determinado objeto, as matérias primas que compõem o objeto, a produção de resíduos sólidos ao final do processo e sobre o destino desses resíduos e os possíveis impactos ambientais decorrentes.

Consideramos oportuno que a criança compreenda todo o ciclo dos produtos, desde a extração da matéria prima até as consequências do descarte no meio ambiente. A modificação de nossos posicionamentos a respeito do consumo e da produção de resíduos sólidos é essencial.

Os Resíduos Sólidos são o resultado do consumo exercido em sociedade, bem como as "sobras" de uma atividade humana diante do meio ambiente, numa perspectiva de ciclo, ou seja, os materiais que possuem possibilidade de retorno a cadeia produtiva. Para tanto, é necessário que esses resíduos sejam tratados e reaproveitados, evitando maiores danos ambientais. Nesse contexto, são pertinentes as ações que visem a redução do consumo de bens e materiais para que sejam produzidos cada vez menos resíduos sólidos.

No entanto, nem todos os resíduos sólidos podem ser tratados e reaproveitados, e são descartados em lixões, aterros controlados ou aterros sanitários, com a concepção de serem inservíveis, inúteis e insalubres ao contexto humano; são, portanto, considerados lixos.

Logarezzi (2006) considera o lixo como algo que não possui "valores potenciais" em sua composição, ao ser descartado após as atividades humanas; ao passo que aos Resíduos Sólidos são atribuídos valores sociais, econômicos e ambientais, sendo passíveis de reciclagem ou reutilização.

Contudo, conforme preconiza a Política Nacional de Resíduos Sólidos, Lei no12.305/2010 (BRASIL, 2010) a palavra "lixo" é substituída pelo termo "Rejeito". Nesse sentido, a Política Nacional de Resíduos Sólidos (BRASIL, 2010) explica que os Rejeitos são: "[...] Resíduos Sólidos, que depois de esgotadas todas as possibilidades de tratamento e recuperação por processos tecnológicos disponíveis e economicamente viáveis, não apresentem outra possibilidade que não a disposição final ambientalmente adequada[...]".

Ainda no contexto dos Resíduos Sólidos, Layargues (2002) aponta a existência de um "cinismo" com relação à Reciclagem. Para ele, muitos consideram a reciclagem como a "grande salvação" para os problemas causados pela destinação dos Resíduos Sólidos na medida em que uma "falsa segurança" se instaura nesse contexto. A reciclagem diminui os impactos diante da redução da extração de matérias primas, mas não altera o estilo de vida, os níveis elevados de consumo.

Por outro lado, Mansor et al. (2010) destacam a realidade dos catadores reconhecendo que pessoas se beneficiam da coleta dos resíduos sólidos, sendo uma alternativa de trabalho junto as empresas, de reciclagem e, portanto, fonte de renda para muitas famílias.

Torna-se necessária à discussão desses temas com as crianças, principalmente as que estão na Educação Infantil, para que compreendam como realizar o descarte seletivo e o que podem fazer para colaborar com a redução do consumo de materiais poluentes no seu contexto vivido.

Acreditamos que a Educação Ambiental em Resíduos Sólidos pode ser realizada na Educação Infantil, a partir de situações cotidianas e de atividades adequadas às possibilidades de compreensão das crianças. Reiteramos e defendemos uma proposta de Educação Ambiental em Resíduos atenta a ideia de ciclo que envolve os processos de extração, produção, consumo, geração de resíduo, descarte e disposição final ou reinserção dos resíduos no ciclo produtivo como matéria-prima, conforme apontam os estudos de Logarezzi $(2006,2010)$.

Vivências na escola a respeito da redução do consumo, de reutilização (por exemplo: reaproveitamento de embalagens, móveis feitos de sucata, construção de brinquedos) e de descarte seletivo são oportunas. Entretanto, chamamos a atenção que "[...] não bastam apenas atitudes "corretas" - como por exemplo separar o lixo seletivamente para ser reciclado se não forem alterados também os valores consumistas, responsáveis por um volume crescente de lixo nas sociedades modernas". (GUIMARÃES, 2013, p. 14). Outro aspecto que não pode ser negligenciado diz respeito às desigualdades sociais no acesso aos bens de consumo. A formação ética inclui a formação humana, a solidariedade e a justiça social.

Investimentos na formação profissional inicial e continuada em Educação Ambiental e o fortalecimento de redes de trabalho entre os professores para o compartilhamento de saberes e vivências são ações importantes para a efetivação da Educação Ambiental nas escolas. Consideramos relevante também a valorização 
dos saberes que os professores constroem por meio da experiência, a partir da articulação entre teoria e prática e as parcerias firmadas com o poder público, as famílias e a comunidade.

Considerando os apontamentos teóricos realizados, destacamos a seguir os dados obtidos por meio das entrevistas semiestruturadas, referentes às concepções das professoras sobre Educação Ambiental, Consumo e Resíduos Sólidos.

Para seis professoras entrevistadas, a Educação Ambiental é "conscientização":

P. 02: É a conscientização; é ensinar para a criança sobre o meio ambiente que ela vive; saber lidar, saber utilizar, aproveitar, respeitar... é isso. (PROFESSORA 2, 2017)

P. 03: Eu acho que a Educação Ambiental não é só os Resíduos Sólidos, mas toda uma conscientização; é você cuidar[...]. (PROFESSORA 3, 2017)

P. 04: Educação Ambiental é a conscientização do planeta, do que tem no nosso planeta e de como a gente deve usar para nosso benefício sem estragar o planeta [...]. (PROFESSORA 4, 2017)

P. 06: Educação Ambiental é a Educação que visa a formação da consciência [...]. (PROFESSORA 6, 2017)

P. 07: Pra mim é a conscientização [...]. (PROFESSORA 7, 2017)

P. 09: Educação Ambiental é você ser consciente [...] eu tenho que ter consciência do que eu estou fazendo e o que futuramente isso vai me trazer [...]. (PROFESSORA 9, 2017)

De acordo com Brondani e Henzel (2010), ao considerarmos a Educação Ambiental como um processo, a conscientização se faz presente nesse contexto, na medida em que ela promove a criação de um senso crítico a respeito do meio ambiente e, a partir disso, poderá ocorrer um compromisso com a aquisição de novos hábitos e atitudes com relação às questões ambientais.

Contudo, é importante ressaltar que uma Educação Ambiental que priorize somente a conscientização corre o risco de limitar as possibilidades de interações com o meio, pois apresenta uma abordagem de conhecimentos apenas no nível intelectual. Neste sentido, faz-se necessário a aquisição de conteúdos conceituais, procedimentais e atitudinais que se materializem em ações concretas em prol de um ambiente saudável.

Por outro lado, as quatro professoras restantes apresentaram posicionamentos diversos a respeito da Educação Ambiental:

P. 01: É trabalhar com eles a relação com o meio que eles vivem, pra que eles consigam entender que já uma interdependência; que nós necessitamos da natureza $\quad[\ldots]$ (PROFESSORA 1, 2017)

P. 05: Pra mim é algo que nós ganhamos da natureza; meio ambiente e Educação Ambiental devem caminhar juntos, pra preservar [...]. (PROFESSORA 5, 2017).

P. 08: Educar para a vida, porque o ambiental não quer dizer só sobre a natureza, mas tem a ver com o ambiente, a nossa casa, nosso bairro [...]. (PROFESSORA 8, 2017).

P. 10: Educação Ambiental vai muito além de jogar o lixo no lixo [...] é o reaproveitamento mesmo dos materiais [...] transformar [...] (PROFESSORA 1, 2017).

Conforme os estudos de Sorrentino et al. (2005), Loureiro (2010), Carvalho (2006) e Sanches (2008), não é possível conceber uma única concepção a respeito do que seja a Educação Ambiental, pois é uma temática que 
envolve questões socioeconômicas, políticas, culturais. Neste sentido, acreditamos que a Educação Ambiental deve perpassar todo um processo de formação do ser humano, com a construção de valores, conceitos e principalmente, atitudes frente aos problemas ambientais e ao contexto vivido de cada um. 0 professor tem um grande papel nesse processo, e por isso, as respostas mencionadas por estas professoras também fazem parte do contexto da Educação Ambiental.

Num segundo momento, perguntamos as professoras quais eram as concepções delas a respeito do tema Consumo. Nesta questão, as professoras também utilizaram de exemplos do seu cotidiano para conceituarem o Consumo, estabelecendo paralelo com o Consumismo infantil.

Seis professoras conceituaram o tema Consumo como "algo ligado a necessidade" "o que precisa", "o que é básico para vida" e o Consumismo como "exagero", "o que extrapola", "o que não precisa", conforme trechos da entrevista semiestruturada:

$$
\begin{aligned}
& \text { P. 01: Consumo é a } \\
& \text { necessidade, } \\
& \text { consumismo é o exagero } \\
& \begin{array}{ll}
\text { [...]. (PROFESSORA } 1 \text {, } \\
\text { 2017). }
\end{array}
\end{aligned}
$$

P. 02: Consumo é aquilo que eu preciso; consumismo é o exagero [...]. (PROFESSORA 2, 2017).

P. 03: O consumismo vai além do que é necessário para o cotidiano da criança [...] são os produtos consumidos de forma exacerbada, sem necessidade; por um impacto da mídia ou influência familiar; o consumo é o que é necessário [...] só isso. (PROFESSORA 3, 2017).

P. 04: O consumo é o que a gente usa pro nosso próprio bem estar; consumismo é quando a gente compra coisas que a gente não precisa [...]. (PROFESSORA 4, 2017).
P. 08: O consumo é o que a pessoa precisa desde que ela nasce, que é básico para vida dele, como fraldas [...] e o consumismo é o que extrapola isso. (PROFESSORA 8, 2017).

P. 09: O consumismo infantil é aquela criança que tudo quer [...] e o pai vai lá e compra [...] a criança tem um monte de brinquedos em casa e cada vez quer mais [...] 0 consumo pra mim é usar o que tem [...] usar só o que precisa. (PROFESSORA 9, 2017).

As respostas obtidas com as seis professoras possuem ligação com os apontamentos de Slater (2002), Portilho (2005), Schor (2009), Dourado e Belizário (2012), Silva (2014), entre outros, que apresentam o Consumo como uma temática ligada a economia e a cultura dominante em um contexto social.

Concordando com Logarezzi (2006, p. 99), atribui-se ao termo "Consumo" o "[...] ato de adquirir e usar produtos e serviços no desenvolvimento de atividades humanas entendidas como necessárias, em determinado contexto cultural e em determinado momento". Logo, o consumo faz parte de nossas atividades básicas do cotidiano, contudo, devemos sempre estar atentos até que ponto esse consumo é necessário ou quando esse consumo se torna descontrolado.

Nessa mesma linha de raciocínio, Cortez (2009, p. 36) afirma que o consumismo é o "[...] ato, efeito, fato ou prática de consumir (comprar em demasia) e consumo ilimitado de bens duráveis, especialmente artigos supérfluos[...]". Silva (2014) alerta para as ações voltadas para o consumismo, na medida em que pode se tornar uma vertente patológica denominada "transtorno do comprar compulsivo", atingindo crianças e adultos.

Três professoras apresentaram conceituações pertinentes a respeito do Consumo e do Consumismo, como exemplificam os trechos das entrevistas semiestruturadas:

P. 05: Pra mim, o consumo é um segmento que acumula e produz muito 
lixo [...] lixo que demora muito para se decompor. o homem e a família moderna vive disso, do consumo desses produtos e os pais não entendem que eles precisam cuidar desse lixo [...]. (PROFESSORA 5, 2017).

P. 06: É a questão do querer, possuir [...] até as vezes coisas que os pais querem ter e não tem condições de possuir [...] Hoje as crianças ficam o dia todo na creche e ai como eles ficam muito tempo na frente da tv também, eles têm a mídia [...] então eu acho que é muita informação e isso que aflora essa questão do consumismo [...]. (PROFESSORA 6, 2017).

P.07: O consumo e o consumismo infantil estão ligados a quanto a mídia explora o que a criança precisa ter [...] sendo que ela não precisa [...] hoje em dia as crianças têm Iphone, Ipad.. [...]. (PROFESSORA 7, 2017).

Portilho (2005) avalia que o consumo faz parte da vida das pessoas e deveria acontecer pela perspectiva do Consumo consciente, ou seja, que as pessoas reduzam o consumo, que consumam apenas os bens e serviços que efetivamente precisam de acordo com suas necessidades diárias e que, na medida do possível, reutilizem os produtos. A partir dessa perspectiva, espera-se ainda que reflitam sobre o ciclo de vida dos produtos, façam uma escolha consciente dos produtos que consomem, realizem o descarte seletivo e colaborem para a gestão eficiente dos mesmos.

Por fim, indagamos as professoras a respeito das concepções que elas possuíam a respeito da temática dos Resíduos Sólidos e Lixo. As professoras P. 01, P. 04, P. 08 e P. 09 apontaram para a concepção de Resíduos Sólidos como "algo que eu utilizo e reaproveito/reciclo" e o lixo, "como o que não dá pra reciclar":
P. 01: Acredito que o resíduo seja o que nós utilizamos, o que sobra das produções deles aqui na escola; o lixo é o que não vai ser utilizado. (PROFESSORA 1, 2017).

P. 04: Resíduo Sólido é o que dá pra reciclar [...] plástico, papel, vidro, lata [...] essas coisas [...] o lixo é aquilo que mistura tudo, você não aproveita nada e ai vai tudo pro lixão e passa anos pra terra consumir aquilo [...]. (PROFESSORA 4, 2017).

P. 08: O Resíduo Sólido é o que a gente pode reaproveitar [...] já o lixo é o que a gente não aproveita, como o lixo de banheiro [...]. (PROFESSORA 8, 2017)

P. 09: O lixo é o que você não vai usar, você descarta [...] E os Resíduos é o que pode ser reaproveitado, [...] a exemplo do sabão que a gente faz com o óleo. (PROFESSORA 9, 2017).

Percebemos que as respostas das professoras P. 01, P. 04, P. 08 e P. 09 estão alinhadas ao que defende Logarezzi (2006). As falas das professoras denotam a compreensão dos Resíduos Sólidos como algo que pode ser reaproveitado, produtos que podem ser novamente utilizados como matéria prima para a elaboração de novos materiais.

Sobarzo (2008, p.33) explica que "[...] essa ideia de inutilidade, aos poucos, vem sendo substituída pela de fluxo de matéria-prima. 0 resíduo ou lixo deve ser compreendido a partir de uma ideia de ciclo (...) o resíduo, ao não ser descartado como "lixo comum" preserva seu status de matéria-prima, fechando assim o ciclo".

Retomando os estudos de Logarezzi (2006, p. 96), lixo é "[...] aquilo que sobrou de uma atividade qualquer e é descartado sem que seus valores (potenciais, econômicos e ambientais) sejam preservados". Em outras 
palavras, o lixo não pode voltar a cadeia produtiva.

Para que a gestão dos Resíduos Sólidos aconteça de forma integrada, Mansor et al. (2010) destacam a importância de ações e decisões pautadas no princípio dos 3"R (três erres): Redução, Reutilização e Reciclagem, que prevê a redução do consumo e o desperdício de materiais, reutilização de produtos e reciclagem de materiais. Os "erres" sugerem discussões sobre a redução do consumo de materiais industrializados que possam agredir o meio ambiente, a reutilização de materiais ou objetos que são tidos como inservíveis e a reciclagem de resíduos sólidos que resultem em novos produtos, fomentando a cadeia produtiva.

$\mathrm{Na}$ medida em que hoje os problemas ambientais podem ser pensados além do que prevê a redução, reciclagem e reutilização; os "3Rs" foram expandidos para "8 Rs", atendendo novas exigências do contexto socioambiental e do consumo consciente dos recursos naturais: refletir, reduzir, reutilizar, reciclar, respeitar, reparar, responsabilizar-se e repassar.

Um posicionamento muito presente na fala das professoras é referente à reciclagem, ao considerar os "resíduos como algo que pode ser reciclado". Layrargues (2002) corrobora com esse posicionamento, dissertando a respeito de um "cinismo" existente sobre a reciclagem, como a "única salvação" para a questão da gestão Resíduos Sólidos. Para o autor, a reciclagem é importante, conteúdo é essencial uma reflexão que priorize a questão da redução de produção de resíduos por meio da redução do consumo.

O conhecimento do professor a respeito da questão dos Resíduos Sólidos é de extrema importância, pois além de fomentar os trabalhos na Educação Ambiental, possibilita a aquisição de hábitos e valores a respeito da destinação correta dos resíduos, o consumo consciente e o ciclo de vida dos produtos.

Trajber e Mendonça (2007, p. 71) afirmam que:

Numa sociedade que se caracteriza pela circulação de tantas identidades e diversidades e, especialmente, no cenário dos espaços educadores sustentáveis, pensar a educação é pensa-la diferente. Hoje, o processo pedagógico requer uma reflexão ambiental para que a distância entre o pensar e - fazer também possa acolher o sentir no processo de criação. Uma educação integral deve incitar não apenas responsabilidades ecológicas, mas convidar para repensarmos nossas próprias vidas e o modelo de sociedade, cuidando do mundo por opção de quem acredita que a chamada educação ambiental não é mero pretexto à coleta seletiva de lixo, mas um convite à ressignificação de nossos modos de vida.

Os dados obtidos nas entrevistas semiestruturadas revelam que as professoras já possuem algumas concepções ligadas com as nossas discussões sobre a Educação Ambiental, Consumo e Resíduos Sólidos. Contudo, destacamos a necessidade de aprofundamento das pesquisas na área de Educação Infantil no tocante às questões ambientais, para que a formação inicial e continuada dos professores que atuam na pré-escola possa ocorrer de forma mais efetiva e colaborativa entre os pares.

\section{CONCLUSÕES}

Investimentos na formação profissional inicial e continuada em Educação Ambiental e o fortalecimento de redes de trabalho entre os professores para o compartilhamento de saberes e vivências são ações importantes para a efetivação da Educação Ambiental nas escolas. Consideramos relevante também a valorização dos saberes que os professores constroem por meio da experiência, a partir da articulação entre teoria e prática, e as parcerias firmadas com o poder público, as famílias e a comunidade.

A Política Nacional de Educação Ambiental (BRASIL, 1999) e as Diretrizes Curriculares Nacionais para a Educação Ambiental (BRASIL, 2012) determinam que a Educação Ambiental ocorra em todos os níveis e modalidades de ensino. No entanto, as pesquisas na área ambiental revelam que a Educação Ambiental na Educação Infantil ainda é incipiente e, muitas vezes, baseada no senso comum. Por outro lado, vale dizer que é consenso entre as professoras entrevistadas a importância da 
Educação Ambiental na Educação Infantil, o que é um primeiro passo.

As pesquisas reiteram a importância da formação inicial e continuada dos professores em Educação Ambiental. Para tanto, são necessários investimentos financeiros por parte do Poder Público para ampliação de programas de formação para os professores em Educação Ambiental.

Considerando as discussões apresentadas neste artigo, destacamos a importância dos trabalhos ambientais na Educação Infantil, valorizando a temática da Educação Ambiental, Consumo e Resíduos Sólidos. É essencial a formação da criança para a percepção e compreensão dos problemas ambientais da sua realidade para que, na medida do possível, possa agir de maneira a amenizá-los ou resolvê-los.

Pode-se perceber que a respeito da Educação Ambiental, a concepção que predomina na fala das professoras diz respeito a conscientização, a partir da relação com o contexto vivido.

A maioria das professoras compreende a distinção entre consumo e consumismo ao definir que o consumo é ligado a necessidade, "ao que precisa", "ao que é básico para a vida" e ao conceituar o consumismo relacionado ao "exagero", ao que "extrapola", ao que "não precisa".

Quatro professoras consideram os Resíduos Sólidos como algo que se você usa e que pode ser reaproveitado/reciclado e o Lixo, como algo que não dá para utilizar/aproveitar. As outras seis professoras não conseguiram expressar a diferença entre os termos.

Acreditamos que a Educação Ambiental em Resíduos Sólidos deve ser realizada na Educação Infantil a partir de situações cotidianas, práticas pedagógicas adequadas às possibilidades de compreensão das crianças, o que inclui uma boa formação inicial e continuada dos professores a respeito das questões ambientais.

Nossa intenção com a realização desta pesquisa foi a de ampliar as discussões sobre a Educação Ambiental no contexto da Educação Infantil, valorizando os conteúdos ambientais para a formação da criança e a aquisição de hábitos, valores e atitudes em prol do meio ambiente.

\section{AGRADECIMENTOS}

Agradecemos às Professoras de Educação Infantil que se dispuseram a participar desta pesquisa, compartilhando seus saberes e vivências na área ambiental e colaborando significativamente para a construção de novos conhecimentos e discussões no que diz respeito a formação de professores de Educação Infantil para a Educação Ambiental.

Nossos agradecimentos também à Coordenação de Aperfeiçoamento de Pessoal de Nível Superior (CAPES) pela concessão de bolsa de estudo durante o desenvolvimento desta pesquisa de Doutorado.

Por fim, agradecemos também ao Programa de Pós-Graduação em Educação da Faculdade de Ciências e Tecnologia, UNESP, pelo suporte acadêmico e científico para a estruturação, desenvolvimento e sistematização da pesquisa.

\section{REFERÊNCIAS}

ALONSO, A. Métodos Qualitativos de Pesquisa: uma introdução. In: ALONSO, A; LIMA, M; ALMEIDA, R. Métodos de Pesquisa em Ciências Sociais: Bloco Qualitativo. São Paulo: SESC São Paulo/CEBRAP, 2016. p. 08-23.

ARAÚJO, R. M. B. A formação dos professores para a Educação Infantil: novos olhares. Revista de Educação do Cogeime, v. 14, n. 27, p. 55-65, dez. $2005 . \quad$ Disponível em: http:www.redemetodista.edu.br/revistas/revista scogeime/index.php/COGEIME/article/viewfile/6 51/595. Acesso em: 01 abr. 2018.

BARROS, V.; TOZONI-REIS,M. Reinventando o ambiente: Educação Ambiental na Educação Infantil. Cadernos de Educação, Pelotas, v. 29, n. 77, p. 131-135, Set./Dez. 2009. Disponível em: http://www.scielo.br/scielo.php?script=sci_arttex $\mathrm{t} \& \mathrm{pid}=\mathrm{S} 0101-$

32622009000100009\&Ing=pt\&tlng=pt. Acesso em: 01 abr. 2018. https://doi.org/10.1590/S010132622009000100009

BORTOLOZZI, A; PERES FILHO, A. Diagnóstico da Educação Ambiental no ensino de Geografia. Cadernos de Pesquisa, n. 109, p. 145-171, mar. $2000 . \quad$ Disponível em: http://www.scielo.br/scielo.php?script=sci_arttet \&pid=S0100-

15742000000100007\&lng=pt\&tlng=pt. Acesso em: 15 abr. 2019. https://doi.org/10.1590/S010015742000000100007 
BRASIL. Ministério do Meio Ambiente. Lei no 9795 de 27 de abril de 1999. Dispõe sobre a educação ambiental, institui a Política Nacional de Educação Ambiental e dá outras providências. Brasília, 27 de abril de 1999. Disponível em: http://www.planalto.gov.br/ccivil_03/LEIS/L9795 .htm. Acesso em: 11 ago. 10.

BRASIL. Ministério do Meio Ambiente. Lei no 12.305, de 02 de agosto de 2010. Dispõe sobre a Política Nacional de Resíduos Sólidos, altera a Lei no 9.605, de 12 de fevereiro de 1998; e dá outras providências. Brasília, 2010. Disponível em: http://www.planalto.gov.br/ccivil_03/_ato20072010/2010/lei//12305.htm. Acesso em: $01 \mathrm{fev}$. 2015.

BRASIL. Ministério do Meio Ambiente. Resolução no 2, de 15 de Junho de 2012. Estabelece as Diretrizes Curriculares Nacionais para a Educação Ambiental. Brasília, 15 de junho de 2012. Disponivel em: http://www.planalto.gov.br. Acesso em: 07 fev. 2015.

BRONDANI, C. J; HENZEL, M. E. Análise sobre a conscientização ambiental em escolas da Rede Municipal de Ensino. Revista Brasileira de Educação Ambiental (REVBEA), v. 5, n. 1, p. 3744, 2010. Disponível em: https://periodicos.unifesp.br/index.php/revbea/a rticle/view/1715 Acesso em: 01 dez. 2017. https://doi.org/10.34024/revbea.2010.v5.1715

CAPITULINO, C. S; ALMEIDA, O. A. Professores da Educação Infantil e a prática da Educação Ambiental: Contexto Educativo. Revista Eletrônica do Mestrado em Educação Ambiental, Porto Alegre, v. 31, p. 117-137, jan./jun. 2014.

CARVALHO, L. M. A temática ambiental e o processo educativo: dimensões e abordagens. In: CINQUETTI, H. C. S., LOgAREZZI, A. (Org.) Consumo e Resíduos: Fundamentos para o Trabalho Educativo. São Carlos: EdUFSCar, 2006. p. 19-41.

CORTEZ, A. T. C. Consumo e Desperdício: as duas faces das desigualdades. In: ORTIGOZA, S. A. G; CORTEZ, A. T. C. (orgs). Da produção ao consumo: impactos socioambientais no espaço urbano. São Paulo: Editora UNESP/Cultura Acadêmica, 2009, p. 35-61.
DEMO, P. Metodologia da Investigação em Educação. Curitiba: IBPEX, 2005.

DOURADO, J; BELIZÁRIO, F. (org). Reflexão e Práticas em Educação Ambiental: discutindo o consumo e a geração de resíduos. São Paulo: Oficina de Textos, 2012.

GADOTTI, M. A carta da Terra na Educação. São Paulo: Editora e Livraria Instituto Paulo Freire, 2010.

GUIMARÃES, M. A Dimensão Ambiental na Educação. Campinas: Papirus, 2013.

LAMBERTUCCl, H. Educação Ambiental e Escola Pública: concepções e práticas pedagógicas nos materiais didáticos institucionais (1988-2005). 2008. 191 f. Dissertação (Mestrado em Educação) - Universidade Estadual Paulista, Instituto de Biociências, Rio Claro-SP, 2008.

MANSOR, M. T. C. et al. Cadernos de Educação Ambiental: Resíduos Sólidos. São Paulo: Governo do Estado de São Paulo, Secretaria do Meio Ambiente, Coordenadoria de Planejamento Ambiental, 2010.

LAYARGUES, P. O cinismo da reciclagem: o significado ideológico da reciclagem da lata de alumínio e suas implicações para a educação ambiental. In: LOUREIRO, F.; LAYARGUES, P.; CASTRO, R. (Orgs.) Educação ambiental: repensando o espaço da cidadania. São Paulo: Cortez, 2002. p. 179-220.

LOGAREZZI, A. Educação Ambiental em resíduo: uma proposta de terminologia. In: CINQUETTI, H.C.S; LOGAREZZI, A. (Orgs.). Consumo e Resíduo: Fundamentos para o trabalho educativo. São Carlos: EduUFSCAR, 2006, p. 85-117.

LOGAREZZI, A. J. M. Educação Ambiental em comunidades de aprendizagem: uma abordagem crítico-dialógica. In: REUNIÃO ANUAL DA ANPED, 33, 2010, Caxambu. Anais... Caxambu, ANPEd, $2010 . \quad$ Disponível em: http://33reuniao.anped.org.br/internas/ver/trab alhos-gt22. Acesso em: 16 abr. 2019.

LOUREIRO, C. F. B. A relação teoria-prática na formação de professores em Educação Ambiental. In: ENCONTRO NACIONAL DE 
DIDÁTICA E PRÁTICA DE ENSINO, 15., 2010, Belo Horizonte. Anais... Belo Horizonte: Autêntica, 2010. (Convergências e Tensões no campo da formação e do trabalho docente) p. 106-123.

LOUREIRO, C. F. B; LAYARGUES, P.; CASTRO, R. (Orgs.) Educação ambiental: repensando o espaço da cidadania. São Paulo: Cortez, 2011.

LUDKE, M; ANDRÉ, M. E. D. A. Pesquisa em Educação: Abordagens Qualitativas. São Paulo: EPU, 1986.

MAXIMO-ESTEVES, L. Da teoria à prática: Educação Ambiental com as crianças pequenas ou o fio da História. Porto: Porto Editora, 1998.

MIELKE, P. E. Princípios da educação ambiental nas práticas e discursos de professores do ensino fundamental. 2010. 164 f. Dissertação (Mestrado em Educação) - Universidade Estadual Paulista, Instituto de Biociências de Rio Claro, $2010 . \quad$ Disponível em: http://hdl.handle.net/11449/90049. Acesso em: 15 abr. 2017.

PORTILHO, F. Sustentabilidade Ambiental, consumo e cidadania. São Paulo: Cortez, 2005.

PROFESSORA 1. Entrevista acerca concepções pedagógicas sobre Educação Ambiental, Consumo e Resíduos Sólidos. Entrevistadores: Natália Teixeira Ananias Freitas e Fátima Aparecida Dias Gomes Marin. Presidente Prudente, 2017. Entrevista concedida para a pesquisa.

PROFESSORA 2. Entrevista acerca concepções pedagógicas sobre Educação Ambiental, Consumo e Resíduos Sólidos. Entrevistadores: Natália Teixeira Ananias Freitas e Fátima Aparecida Dias Gomes Marin. Presidente Prudente, 2017. Entrevista concedida para a pesquisa.

PROFESSORA 3. Entrevista acerca concepções pedagógicas sobre Educação Ambiental, Consumo e Resíduos Sólidos. Entrevistadores: Natália Teixeira Ananias Freitas e Fátima Aparecida Dias Gomes Marin. Presidente Prudente, 2017. Entrevista concedida para a pesquisa.
PROFESSORA 4. Entrevista acerca concepções pedagógicas sobre Educação Ambiental, Consumo e Resíduos Sólidos. Entrevistadores: Natália Teixeira Ananias Freitas e Fátima Aparecida Dias Gomes Marin. Presidente Prudente, 2017. Entrevista concedida para a pesquisa.

PROFESSORA 5. Entrevista acerca concepções pedagógicas sobre Educação Ambiental, Consumo e Resíduos Sólidos. Entrevistadores: Natália Teixeira Ananias Freitas e Fátima Aparecida Dias Gomes Marin. Presidente Prudente, 2017. Entrevista concedida para a pesquisa.

PROFESSORA 6. Entrevista acerca concepções pedagógicas sobre Educação Ambiental, Consumo e Resíduos Sólidos. Entrevistadores: Natália Teixeira Ananias Freitas e Fátima Aparecida Dias Gomes Marin. Presidente Prudente, 2017. Entrevista concedida para a pesquisa.

PROFESSORA 7. Entrevista acerca concepções pedagógicas sobre Educação Ambiental, Consumo e Resíduos Sólidos. Entrevistadores: Natália Teixeira Ananias Freitas e Fátima Aparecida Dias Gomes Marin. Presidente Prudente, 2017. Entrevista concedida para a pesquisa.

PROFESSORA 8. Entrevista acerca concepções pedagógicas sobre Educação Ambiental, Consumo e Resíduos Sólidos. Entrevistadores: Natália Teixeira Ananias Freitas e Fátima Aparecida Dias Gomes Marin. Presidente Prudente, 2017. Entrevista concedida para a pesquisa.

PROFESSORA 9. Entrevista acerca concepções pedagógicas sobre Educação Ambiental, Consumo e Resíduos Sólidos. Entrevistadores: Natália Teixeira Ananias Freitas e Fátima Aparecida Dias Gomes Marin. Presidente Prudente, 2017. Entrevista concedida para a pesquisa.

PROFESSORA 10. Entrevista acerca concepções pedagógicas sobre Educação Ambiental, Consumo e Resíduos Sólidos. Entrevistadores: Natália Teixeira Ananias Freitas e Fátima Aparecida Dias Gomes Marin. Presidente 
Prudente, 2017. Entrevista concedida para a pesquisa.

RODRIGUES, C. Educação Infantil e Educação Ambiental: um encontro das abordagens teóricas com a prática educativa. Revista Eletrônica do Mestrado em Educação Ambiental. v. 26, p. 169482, jan./jun. 2011.

RUFFINO, S. F. A Educação ambiental nas escolas municipais de educação infantil de São CarlosSP. 2003. 109 f. Dissertação (Mestrado em Educação) Departamento de Metodologia de Ensino, Universidade Federal de São Carlos, São Carlos, 2003.

SANCHES, L. Avaliação de impacto ambiental: conceitos e métodos. São Paulo: Oficina de Textos, 2008.

SCHOR, J.B. Nascidos para comprar: uma leitura essencial para orientarmos nossas crianças na era do consumismo. São Paulo: Editora Gente, 2009.

SEVERINO, A. J. Metodologia do Trabalho Científico. São Paulo: Cortez Editora, 2007.

SILVA, A. B. B. Mentes Consumistas: do consumismo à compulsão por compras. São Paulo: Globo, 2014.

SLATER, D. Cultura do Consumo e Modernidade. São Paulo: Nobel, 2002.

SORRENTINO, M. (et al). Educação Ambiental como política pública. Educação e Pesquisa, São Paulo, v. 31, n. 2, p. 285-299, maio/ago. 2005. Disponível em: http://www.diagramaeditorial.com.br/cescar/ma terial_didatico/ea-como-politicapublica. pdf. Acesso: $\quad 01 \quad$ jan. 2018. https://doi.org/10.1590/S1517-

$\underline{97022005000200010}$

SOBARZO, L.C.D. Resíduos Sólidos: Do conhecimento Científico ao Saber Curricular - a releitura do tema em livros didáticos de Geografia. 2008. Tese (Doutorado em Geografia). Faculdade de Ciências e Tecnologia, Universidade Estadual Paulista, Presidente Prudente - SP, 2008.

TIRIBA, L. Crianças, natureza e Educação Infantil. 2005. 249 f. Tese (Doutorado em Educação) -
Pontifícia Universidade Católica do Rio de Janeiro, Rio de Janeiro/RJ, 2005.

TRAJBER, R.; MENDONÇA, P.R. (orgs). o que dizem as escolas que dizem que fazem Educação Ambiental? Brasília: Ministério da Educação, 2007. 